https://helda.helsinki.fi

\title{
On Virtue, Credit and Safety
}

\section{Hirvelä, Jaakko}

2018-02

Hirvelä, J 2018 , ' On Virtue, Credit and Safety ' , Grazer Philosophische Studien , vol. 95 , no. 1 , pp. 98-120 . https://doi.org/10.1163/18756735-000033

http://hdl.handle.net/10138/299895

https://doi.org/10.1163/18756735-000033

acceptedVersion

Downloaded from Helda, University of Helsinki institutional repository.

This is an electronic reprint of the original article.

This reprint may differ from the original in pagination and typographic detail.

Please cite the original version. 


\title{
forthcoming in Grazer Philosophische Studien
}

\section{ON VIRTUE, CREDIT AND SAFETY}

\section{Jaakko Hirvelä}

\section{(University of Helsinki)}

\author{
jaakko.hirvela@helsinki.fi
}

\begin{abstract}
According to robust virtue epistemology, the difference between knowledge and mere true belief is that in cases of knowledge, the subject's cognitive success is attributable to her cognitive agency. But what does it take for a subject's cognitive success to be attributable to her cognitive agency? A promising answer is that the subject's cognitive abilities have to contribute to the safety of her epistemic standing with respect to her inquiry, in order for her cognitive success to be attributable to her cognitive agency. Call this idea the contribution thesis. I will argue that the contribution thesis follows naturally from virtue epistemological accounts of knowledge, and that it is precisely the contribution thesis that allows the virtue epistemologist to deal with a wide variety of objections. Nevertheless, the principal aim of this paper is to argue that virtue epistemological theories of knowledge that are committed to the contribution thesis are ultimately untenable. There are cases of knowledge where the subject's cognitive abilities do not improve the safety of the subject's belief.
\end{abstract}

Keywords: Virtue epistemology; Safety; Credit; Knowledge

\section{Introduction}

According to robust virtue epistemology, the difference between knowledge and mere true belief is that in cases of knowledge, the subject's cognitive success is attributable to her cognitive agency. But what does it take for a subject's cognitive success to be attributable to her cognitive agency? One way of answering this question would be to claim that the subject's cognitive abilities have to contribute to the safety of her epistemic standing with respect to her inquiry in order for her cognitive success to be attributable to her 
cognitive agency. Call this idea the contribution thesis. In Section 2, I will argue that the contribution thesis follows naturally from virtue epistemological accounts of knowledge, and that it is the contribution thesis that allows the virtue epistemologist to deal with cases of testimonial knowledge and with cases featuring environmental luck. In Section 3, I will nevertheless argue that virtue epistemological theories of knowledge that endorse the contribution thesis are ultimately untenable. There are cases of knowledge where the subject's cognitive abilities do not improve the safety of the subject's belief, and hence cases of knowledge where the truth of the subject's belief is not attributable to the subject's cognitive abilities. In Section 4, I will present two ways in which we may continue practicing virtue epistemology, while abandoning the claim that in all cases of knowledge, the truth of the subject's belief must be attributable to her cognitive abilities.

\section{Virtue and Safety}

The central idea of virtue epistemology is that knowledge is a cognitive success that is attributable to the subject's cognitive abilities. Knowledge is not just a belief that is true and competently formed. After all, in Gettier cases the subject gains a true belief by using her cognitive abilities but nevertheless lacks knowledge. In order to solve the Gettier problem, virtue epistemologists have relied on the idea of manifestation, attribution, and credit. The subject's belief must be true because she used her cognitive abilities in order for her belief to qualify as knowledge. A subject who has been gettiered might exhibit cognitive ability in acquiring a true belief, but her belief is not true because it was competently formed. By demanding that the subject's cognitive success has to be attributable to the subject's cognitive abilities, virtue epistemologists are able to solve the Gettier problem.

But when exactly is a cognitive success properly attributable to one's cognitive abilities? Virtue epistemologists have offered two influential answers to this question. According to Sosa $(2007,2009)$, the truth of a subject's belief is properly attributable to the subject's cognitive abilities just in case the subject's cognitive abilities are manifested in the truth of the subject's belief. Greco (2010) has offered an alternative proposal, according to which explanatory considerations matter when determining whether a cognitive success is properly attributable to the subject's cognitive abilities. On Greco's account, a subject deserves credit for her cognitive success just in case her cognitive abilities are the best causal explanation for the fact that she gained a true belief rather than a false belief. 
Even though virtue epistemological theories of knowledge are able to deal with standard Gettier cases, they face two major objections. Firstly, Lackey $(2007,2009)$ has argued that in cases of testimonial knowledge the truth of the subject's belief is not attributable to the subject's cognitive abilities. According to Lackey, what explains why the subject gained a true belief through testimony has everything to do with the testifier's cognitive abilities and almost nothing with the subject's cognitive abilities. Therefore, the truth of the subject's belief cannot be properly attributable to her cognitive abilities. Secondly, it seems that in the famous barn façade case, the truth of the subject's belief is attributable to his cognitive abilities, even though he lacks knowledge (Pritchard 2010, 35-36). Here is the case:

BARN FAÇADE: Barney is driving through the countryside with his daughter and is identifying various objects to amuse her. Barney has excellent eye-sight, and the perceptual conditions are fine when he sees a barn ahead and points towards it, asserting "That's a barn" and forms the corresponding true belief. Unbeknownst to Barney, however, he has entered a barn-façade county, where nearly every structure that looks like a barn is in fact a barn façade that would fool anyone. Luckily he happened to point at the only real barn in the area. ${ }^{1}$

Barney actually sees the barn ahead and his perceptual abilities are working perfectly well. Hence it seems that the truth of his belief is attributable to his cognitive abilities, but nevertheless there is a strong intuition that Barney lacks knowledge because he would have been fooled by the nearby fakes that are dotted across the landscape.

These two problems threaten to tear virtue epistemology asunder. In order to deal with cases featuring testimonial knowledge, the virtue epistemologist would have to weaken the conception of credit in such a way that the truth of a subject's belief can be properly credited to the subject, even if it is not primarily creditable to the subject. Cases of environmental luck, on the other hand, pull the view to the opposite direction; in order to deal with such cases, the virtue epistemologist would have to strengthen the notion of credit in such a way that Barney does not deserve credit for his true belief. ${ }^{2}$ Pritchard $(2010,43)$ has argued

\footnotetext{
${ }^{1}$ This case appears in Goldman $(1976,772)$, though he credits Carl Ginet for it.

${ }^{2}$ Pritchard $(2010,36)$ has introduced the notion of environmental luck. Environmental luck differs from the kind of luck that can be found in standard Gettier cases. In Gettier cases, the luck 'intervenes' between the fact and the subject in such a way that the subject's belief is true. In cases of environmental luck, there is no fissure between the fact and the
} 
that virtue epistemological theories of knowledge that aim to define knowledge solely in virtue-theoretic terms (which he labels robust virtue epistemological theories) cannot solve these two problems simultaneously. Pritchard's solution is to abandon robust virtue epistemology in favor of modest virtue epistemology, which supplements the virtue-theoretic condition with a separate anti-luck condition, designed to rule out all cases of knowledge undermining luck $(2010,2012)$. The anti-luck condition that Pritchard is drawn to is the safety condition. Very roughly, a subject's true belief is safe only if the belief could not easily have been false. Before moving onwards, it is useful to make this vague characterization of the safety condition more explicit.

Usually the safety condition is fleshed out in terms of a possible-worlds heuristic. Following Pritchard (2007, 292) let us define safe belief as follows:

SAFETY: a subject S's true belief that $p$ is safe if, and only if

(i) in nearly all nearby possible worlds, and in all of the very closest possible worlds, where $\mathrm{S}$ believes that $p$ (via the same method $\mathrm{M}$ that she uses in the actual world), her belief will continue to be true. ${ }^{3}$

The space of possible worlds is centered on the actual world and branches out according to a similarity ordering. Worlds that are very close to the actual world are very similar to it, and worlds that are further away are less similar to it. A subject's belief is safe only if her belief matches the truth in the range of nearby possible worlds. Given that the very closest worlds represent possibilities that could very easily have obtained, it is natural that we place greater emphasis on those worlds and require that the subject does not form any false beliefs in them. As we travel further away from the actual world, we become more tolerant to false beliefs, until the possibility of forming a false belief does not threaten the safety of a subject's epistemic position.

subject, but the environment in which the subject finds herself in ensures that the subject could very easily have formed a false belief instead. Both environmental and intervening epistemic luck undermine knowledge.

${ }^{3}$ Different versions of the safety condition have been offered as a necessary condition for knowledge by Luper (2003), Sainsbury (1997), Sosa (1999), Williamson (2000), Greco (2012), and Pritchard (2005, 2012), among others. For arguments against the necessity of the safety condition see Neta and Rohrbaugh (2004), Bogardus (2014), and Hawthorne and Lasonen-Aarnio (2009). The above version of the safety condition is trivially satisfied if the subject believes in a necessary truth. I (2017a, 2017b) have argued that the safety condition should be relativized to a set of propositions in order to deal with the problem of necessary truths. For present purposes we need not worry about this complication. 
Now that we have a properly formulated safety condition at our disposal, we should look at how proponents of robust virtue epistemology have responded to the challenge raised by the barn-façade case. Interestingly, many proponents of robust virtue epistemology have responded to the barn-façade case by claiming that by satisfying the virtue-theoretic condition, one will satisfy a properly formulated safety condition, making the retreat to modest virtue epistemology unnecessary. Here are a few representative quotations from robust virtue epistemologists:

[I]t looks like one must satisfy some sort of safety principle by virtue of satisfying the ability condition (Littlejohn 2014, 379).

If the correctness of S's belief depends (sufficiently) on S's cognitive ability, then p's safety is ensured (Carter 2016, 142).

For the truth of a perceptual belief to be credited to the believer, this belief has to be safe (Gaultier 2014, 486).

I have argued that knowledge requires both virtue and safety, and that the virtue condition (properly understood) entails the safety condition (properly understood) (Greco 2016, 52).

So, his judgement can then be apt only if safe. Accordingly, Barney knows full well only if his constitutive judgment is safe (Sosa 2015, 79). ${ }^{4}$

Accordingly, these robust virtue epistemologists subscribe to the following entailment thesis: if the truth of a subject's belief is properly attributable to her cognitive abilities, then the belief is safe. If this entailment thesis is true, then robust virtue epistemologists are able to deal with the barn-façade case, since Barney's belief could easily have been false, and therefore it is not safe. Moreover, as I will argue below, once the entailment thesis is properly understood, it allows the virtue epistemologist to deal with cases of testimonial knowledge as well.

But how should we understand the entailment thesis? Since it is a very strong modal claim, the relation between virtue and safety should not be one of mere correlation. Preferably, the virtue-theoretic condition

\footnotetext{
${ }^{4}$ Note that Sosa is talking here about knowledge full well, not of animal knowledge. According to Sosa, knowledge full well entails safety, whereas animal knowledge does not (Sosa 2007, 35-36).
} 
and the safety condition should not be extensionally equivalent according to robust virtue epistemologist lights. On the very least, the virtue-theoretic condition should be explanatorily more fundamental than the safety condition. Otherwise a purely modal theory of knowledge that contained only the safety condition would be on par with the virtue epistemological theory. Therefore, the relation between virtue and safety needs to be one where the virtue-theoretic component contributes to the safety of the belief. Only in such cases would we say that the belief is properly attributable to the subject's cognitive agency.

It is important to note that virtue epistemologists claim that the mere coincidence of virtue and safety does not suffice for knowledge. The safety of the belief has to be attributable to the subject's cognitive abilities. Otherwise the virtue-theoretic condition could not be explanatorily more basic. Even Pritchard, who rejects the entailment thesis, thinks that the virtue-theoretic condition and the safety condition need to be tied together in a dynamic way. To see this, consider the following passages:

When we attribute knowledge we do not merely want the agent's cognitive agency to play a significant role in her cognitive success, but we further want the agent's cognitive agency to play a significant role in her safe (i.e., non-lucky) cognitive success (Pritchard 2015, 109110).

Your belief is ample just in case its safety (not just its truth) manifests your competence. [...] Call the outcome of an ample performance an ample achievement, and call the view that knowledge is ample belief the ample achievement account of knowledge [...] (Turri 2016, 129).

[S]afety must have its seat in S's cognitive abilities (or virtue), where an ability is understood as a broader disposition to form safe beliefs in a relevant field under relevant conditions. Put another way, knowledge requires agent-based safety, or safety that is grounded in the cognitive abilities of the knower (Greco 2007, 302).

He too might contribute to the existence of his belief, without contributing to its success, to its hitting the mark of truth. And the aptness of his belief requires that he make a contribution, 
which may be quite limited and small, to his belief's correctness and not just to its existence (Sosa 2011, 89-90).

Virtue epistemologists who think that the virtue-theoretic condition and the safety condition are necessary conditions for knowledge claim that the virtue-theoretic component of their view must contribute to the safety of the subject's belief. This is true even of those virtue epistemologists who reject the entailment thesis, but who nevertheless think that virtue and safety are necessary for knowledge. Therefore, it is fair to say that both modest and robust virtue epistemologists (who think that safety is a necessary condition for knowledge) subscribe to the following contribution thesis: in order for a subject's true belief to qualify as knowledge, the subject's cognitive abilities must contribute to the safety of the subject's belief.

One might hesitate whether Sosa is committed to the contribution thesis. After all, he claims only that the subject's cognitive abilities must contribute to the correctness of the belief, and not just to its existence. He does not explicitly state that the subject's cognitive abilities have to contribute to the safety of her belief. The reason why Sosa is committed to the contribution thesis is that Sosa, like other robust virtue epistemologists, holds that knowledge can be defined as a true belief that is creditable to the subject's cognitive abilities, and that knowledge is incompatible with epistemic luck. Assuming that the safety condition is able to exclude the kind of luck that is incompatible with knowledge possession, it must be the case that the facts in virtue of which a subject's true belief amounts to knowledge also help to establish that the belief is not true as a matter of good epistemic luck. In other words, the facts that ensure that the truth of a subject's belief is creditable to her cognitive abilities must help to ensure that the belief is safe to some extent. Therefore, if the truth of a subject's belief is properly creditable to her cognitive abilities, her cognitive abilities must contribute to the safety of her belief.

Sosa thinks that one's cognitive abilities have to contribute to the correctness of one's belief even in cases of animal knowledge. Therefore, he is committed to the contribution thesis at the level of animal knowledge. One way to put the difference between knowledge full well and animal knowledge then is this: both knowledge full well and animal knowledge require that the subject's cognitive abilities contribute to the safety of the subject's belief, but in addition to this, knowledge full well demands that the subject's cognitive abilities contribute to the safety of the subject's belief to the extent that the belief is thereby fully safe. 
Now that we have established that many virtue epistemologists are committed to the contribution thesis, let us look how the contribution thesis allows virtue epistemologists to deal with cases of testimonial knowledge.

The case of knowledge without credit that Lackey $(2007,352)$ offers goes as follows:

CHICAGO VISITOR: Jenny has just arrived to Chicago and asks for directions to Sears Tower from the first adult passer-by that she sees. As it happens, the passer-by knows Chicago extraordinarily well and provides Jenny with impeccable directions to Sears Tower, by telling her that it is located two blocks to the east of the train station. Jenny confidently forms the corresponding true belief.

Lackey's assessment of the case is that we should not credit Jenny with the truth of her belief. Rather the credit should fall to the helpful passer-by. After all, it is the passer-by's city-knowledge that explains why Jenny ended up with a true belief rather than a false belief.

Both Pritchard $(2010,40-41)$ and Sosa $(2011,90)$ have responded to this problem by making a distinction between primary and partial credit. They concede that in cases of testimonial knowledge, the truth of the subject's belief is not primarily creditable to the subject, but nevertheless maintain that it is partially creditable to the subject. Furthermore, they claim that a cognitive success can be properly attributable to a subject's cognitive agency even if it is only partially creditable to the subject.

I think it is plausible that Jenny's cognitive success is at least partially creditable to her, given that she has knowledge. After all, Jenny's cognitive abilities do explain, to some extent, why she gained a true belief rather than a false belief. In explaining why the belief is partially creditable to Jenny, both Pritchard and Sosa argue that Jenny's cognitive abilities help her to avoid forming a false belief. Jenny has to be a careful enough listener, so that she could not easily have misinterpreted the passer-by, in order for her cognitive success to be properly attributable to her cognitive abilities (Sosa 2011, 90). Moreover, it has to be the case that Jenny would not have asked the directions from just about anyone, or believed just about any crazy answer (Pritchard 2010, 41). Her cognitive abilities must help her to avoid error. They have to ensure at least to some extent that her belief is true rather than false. In essence, her cognitive abilities must improve the safety of her belief. The fact that the truth of a belief is attributable to the subject's cognitive agency entails 
that the subject is able to avoid error in a wider scope of possible worlds than she would have been if she would not have exercised her cognitive abilities. Only when a subject's cognitive abilities enhance the safety of her epistemic position with respect to her inquiry, can her cognitive abilities contribute to the safety of her belief. In order for a subject's cognitive abilities to enhance her epistemic position with respect to her inquiry, the fact that she formed her belief in a virtuous manner has to expand the scope of possible worlds where her belief continues to be true. The contribution thesis should be understood along these lines.

Notice that this reading of the contribution thesis does not entail that a true belief that is competently formed, and attributable to the subject's cognitive abilities, would thereby be fully safe. It entails only that the belief must be safer than it would have been if it were not the product of the subject's cognitive abilities. Accepting the contribution thesis does not entail accepting the entailment thesis, and therefore Pritchard can accept the former while denying the latter.

Moreover, it seems that it is actually the contribution thesis that does all the work in the responses that robust virtue epistemologists who defended the entailment thesis have offered when they encounter cases of environmental luck. Consider for example the following passage by Littlejohn:

To know that something is an $\mathrm{F}$ by looking, it seems that vision has to make something available to the subject that would function as a basis for a classificatory judgment by virtue of discriminating the Fs from the non-Fs (2014, 376, emphasis mine).

This sounds eminently plausible. After all, if it was not the subject's perceptual abilities that allowed her to discriminate between F's and non-F's, then how could the truth of her belief possibly be attributable to her cognitive agency? Moreover, if it is the case that the subject's perceptual abilities allowed her to distinguish between F's and non-F's, then her perceptual abilities made her epistemic position safer than it would have been if the subject had lacked those perceptual abilities. The way in which Littlejohn dismantles the barnfaçade case follows straightforwardly from these remarks: in the barn-façade case, Barney's perceptual abilities do not enable him to tag onto some distinguishing mark that real barns have that fake ones lack. Therefore, Barney lacks knowledge. His cognitive abilities did not improve (enough) the safety of his epistemic position. 
Let us take stock. The way in which virtue epistemologists are able to deal with cases featuring environmental luck and with cases of testimonial knowledge is essentially grounded in the contribution thesis. In cases featuring environmental luck, the subject's cognitive abilities do not enhance the safety of the subject's belief to a sufficient extent. Barney's belief could easily have been false. His cognitive abilities did not allow him to avoid the possibility of error to a high enough degree. Therefore, the truth of Barney's belief is not creditable to his cognitive agency, and he does not satisfy the virtue-theoretic condition.

The way in which virtue epistemologists are able to deal with cases of testimonial knowledge hinges on the same principle idea. In such cases, the subject's cognitive abilities do enhance the safety of the subject's epistemic position to a sufficient extent. Therefore, the cognitive success that Jenny attains is attributable to her cognitive agency, since her cognitive abilities allowed her to avoid error to a sufficient extent. Given that Jenny is in a friendly epistemic environment, her cognitive abilities do not have to increase the safety of her epistemic position very much. Perhaps it is enough that her cognitive abilities allow her to dodge some error possibilities, as Pritchard and Sosa suggest.

This seems to indicate that there is some truth in the epistemic dependency thesis advocated by Kallestrup and Pritchard (2013). According to the epistemic dependency thesis, knowledge can be dependent on factors that are completely external to one's cognitive agency. This thesis has both a negative and a positive aspect: sometimes external factors can deprive one of knowledge even though one exhibits cognitive abilities in a quite robust sense, and sometimes external factors can ensure that one has knowledge, even though one exhibits so little cognitive virtue that one would not have gained knowledge if one had happened to be in a somewhat less friendly epistemic environment. Kallestrup and Pritchard have argued that robust virtue epistemologists are unable to accommodate the epistemic dependency thesis, and that robust virtue epistemology is therefore untenable.

However, if robust virtue epistemologists can accept the contribution thesis, then it seems that they can accept the epistemic dependency thesis as well. The reason for this is that the contribution thesis is best understood as placing a restriction that submits to degrees. In relatively friendly epistemic environments, such as the one in which Jenny finds herself in, a relatively low enhancement on the subject's epistemic safety is called for. If Jenny were in a more unfriendly environment, a quite high display of epistemic 
competence would be in order. Similarly, if Barney were to gain knowledge in his unfortunate circumstances, he would have to use his cognitive abilities quite extensively to improve the safety of his epistemic position in order to reach the appropriate threshold. Robust virtue epistemologists who accept the contribution thesis are thus in a position to accept the epistemic dependency thesis contra Kallestrup and Pritchard. In some cases, the subject's epistemic environment calls for greater epistemic effort than in others. This is perfectly in line with robust virtue epistemological theories of knowledge that accept the entailment and contribution theses.

\section{Knowledge without Credit}

Thus far we have seen that the contribution thesis is at the center of virtue epistemological theories of knowledge that maintain that the safety condition is a necessary condition for knowledge. By accepting the contribution thesis, the robust virtue epistemologist is able to accommodate cases featuring environmental luck, cases of testimonial knowledge, and the epistemic dependency thesis. In the remaining part of this paper, I want to cast doubt on virtue epistemological theories of knowledge that subscribe to the contribution thesis. I will argue that there are cases of knowledge where the subject's cognitive abilities do not enhance the safety of the subject's belief to any extent. If there are such cases, then a subject can have knowledge even if the truth of the subject's belief is not attributable to her cognitive abilities.

The idea behind the contribution thesis is that in order for the truth of a subject's belief that $p$ to be attributable to the subject's cognitive abilities, the fact that the subject formed the belief through her cognitive abilities must increase the safety of the subject's epistemic position with respect to her inquiry whether $p$. As such, the contribution thesis is a relatively weak thesis. While I have no argument against the contribution thesis, I will propose a counterexample against those theories of knowledge that combine the contribution thesis with a virtue-theoretic condition, which states that in order for a subject's belief that $p$ to amount to knowledge the truth of that belief has to be attributable to the subject's cognitive abilities.

In order to formulate the counterexample that I have in mind, consider the following passage from Sosa, in which he describes a way in which a successful performance that is the product of the subject's abilities can fail to be creditable to the subject's competence: 
[I]f an archer shoots a metal-tipped arrow, and the target is a super-powerful magnet, he would earn minimal credit at most for his successful shot. Suppose any shot, anywhere near that target would end up in the bull's eye.

The success of an archer's shot is creditable, attributable to the exercise of a competence, only if the external conditions are appropriate for the manifestation of that competence, and this will include appropriate wind conditions, absence of powerful magnets, et cetera. (Sosa 2011, 87, emphasis mine)

Sosa thinks that in order for the archer's shot to be creditable to him, the archer has to contribute to the success of the shot. If the external conditions are such that the subject is guaranteed to succeed, his competence cannot contribute to the success of that shot, because he would have hit the target even if he was a lousy shot. Translated to the epistemic case, a subject's cognitive success can be properly attributable to the subject's cognitive agency just in case the subject's cognitive abilities contribute to the truth of her belief. If the external conditions are such that the subject is guaranteed to gain a true belief, her cognitive abilities cannot contribute to the truth of her belief because she would have gained a true belief even if she was a vicious epistemic agent. A subject who is in an epistemic position where she cannot gain any false beliefs, where this fact does not depend on the subject's virtuous epistemic nature, cannot satisfy the contribution thesis. If a subject in such a situation can gain knowledge, then virtue epistemological theories that accept the contribution thesis have a genuine counterexample.

Consider the following case of perceptual knowledge:

ORDINARY PERCEPTION: Agnes is a normal epistemic agent who has the same epistemic virtues that most of us have. At the moment, Agnes is sitting at her desk and forms the true belief that her coffee cup is on the table on the basis of seeing it on the table, thereby coming to know that her coffee cup is on the table.

Virtue epistemological theories of all strands can accommodate this case of perceptual knowledge. After all, given how the case is set up, it is evident that the truth of Agnes' belief is attributable to her cognitive agency. The fact that she has excellent eyesight improves considerably the safety of her epistemic standing. The problem emerges, however, once we make an alteration to the case. 
GUARDIAN ANGEL: Agnes is a normal epistemic agent who has the same epistemic virtues that most of us have. At the moment, Agnes is sitting at her desk and forms the true belief that her coffee cup is on the table on the basis of seeing it on the table. Unbeknownst to Agnes, however, she is protected by a guardian angel, who will ensure that Agnes never forms false beliefs. The angel will not intervene with Agnes' beliefforming process if she is about to form a true belief, but will stop the belief-forming process if Agnes is about to form a false belief. Moreover, the angel has tremendous interest that Agnes does not form any false beliefs, and therefore she is guarding Agnes in all possible worlds. Since Agnes forms a true belief, the angel does not interrupt Agnes' belief-forming process.

In this case, Agnes is guaranteed to form only true beliefs. Her epistemic position is thus maximally safe. There are no possible worlds where Agnes believes that her coffee cup is on the table, while it is not on the table. In fact, there are no possible worlds where she forms any false beliefs. The question is: does Agnes still know that the coffee cup is on the table?

To me it seems evident that Agnes knows that her coffee cup is on the table. All that has changed is that she is in a much friendlier epistemic environment. How could a subject lose knowledge simply by moving into an environment where she cannot form false beliefs? How could the fact that one cannot err, even if this fact is external to one's cognitive agency, ever rob one of knowledge? But that is precisely what the virtue epistemologist must claim if she accepts the contribution thesis. The reason for this is that Agnes is maximally safe from error. She would have gained a true belief whether she was a virtuous epistemic agent or not. Her cognitive abilities cannot enhance the safety of her epistemic standing, because she is maximally safe from error thanks to the guardian angel. Therefore, her cognitive success is not attributable to her cognitive agency and she cannot satisfy the virtue-theoretic condition for knowledge.

The case is analogous to Sosa's case of an archer who is shooting arrows at a super-powerful magnet. The archer could not have missed his target, nor could Agnes have missed hers. According to Sosa, the presence of the magnet makes the circumstances for archery inappropriate. Accordingly, the presence of the guardian angel should make the circumstances for belief inappropriate. However, as we have noticed, the intuition that Agnes acquires knowledge is fairly strong. Therefore, her epistemic situation cannot render her unable to have perceptual knowledge. In fact, her epistemic situation would seem to be one that allows her to gain 
knowledge quite easily. Virtue epistemological theories of knowledge that accept the contribution thesis cannot grant Agnes with knowledge. Therefore, such theories have a clear-cut counterexample.

At this point it is worth emphasizing that GUARDIAN ANGEL is not an epistemic Frankfurt case and thus is not analogous to the case that Kelp (2016a) mounts against virtue-epistemological theories of knowledge. In epistemic Frankfurt cases, the subject is compelled to form a certain belief unless she forms that belief out of her own accord. Here is Kelp's case:

DEMON: An evil-demon has resolved that Chris should form the belief that it is 8:22 a.m. (whether this is true or not) by looking at a grandfather clock when he comes down the stairs. The demon can ensure that Chris forms this belief, but since the demon is lazy, he will act only if Chris doesn't form the belief out of his own accord. As it happens, Chris comes down at 8:22 and forms the belief that it is $8: 22$ by looking at the grandfather clock. The demon doesn't intervene. $(2016 \mathrm{a}, 28)$

DEMON is not analogous to GUARDIAN ANGEL since Agnes could have withheld her judgment. Chris, however, will believe that it is $8: 22$, either through his own means or by being compelled by the demon. Secondly, whereas in GUARDIAN ANGEL Agnes is directed at truth - in that Agnes could not have formed any false beliefs at all -, in Frankfurt-style cases, the subject is directed at forming some specific belief, no matter whether the belief is true or false. Thirdly, whereas the demon causes Chris to form the belief that it is 8:22 in counterfactual situations, in GUARDIAN ANGEL, the angel never causes Agnes to believe anything. Finally, whereas Agnes is safe from error, Chris is not. Therefore, if DEMON is a counterexample against virtue-epistemological theories of knowledge, it is distinct from GUARDIAN ANGEL.

But even though Agnes' cognitive abilities cannot enhance the safety of her belief, could they contribute to the explanation as to why Agnes' epistemic state is safe? If they do contribute to the explanation as to why Agnes is in a safe epistemic state, then virtue epistemologists could reinterpret the contribution thesis and say that the truth of a subject's belief is creditable to her cognitive abilities just in case her cognitive abilities help to explain why the belief is safe. ${ }^{5}$

\footnotetext{
${ }^{5}$ I would like to thank an anonymous referee for offering this objection.
} 
Whether the subject's cognitive abilities help to explain in a robust enough sense why Agnes' belief is safe in GUARDIAN ANGEL is a difficult question. What muddies the waters here, I think, is that Agnes' cognitive abilities are part of the causal explanation as to why she gained a true belief in the actual world. However, as the barn-façade case illustrates, the fact that the subject's cognitive abilities are causally related to the truth of her belief does not ensure that the truth of the subject's belief is creditable to her cognitive abilities. But since it might be controversial whether Agnes' cognitive abilities help to explain the safety of her epistemic standing in the guardian angel case, I will offer a slightly altered version of the case, where it is intuitively clear that the subject's cognitive abilities do neither enhance nor explain the safety of the subject's epistemic standing. In order to do this, consider the following pair of cases:

FAKE CUPS: Coop is a normal epistemic agent who has the same epistemic virtues that most of us have. At the moment, Coop is in the cafeteria and is about to take some coffee. He sees a cup on the serving table and forms the true belief that "That's a cup". Unbeknownst to Coop, however, all of the other cups in the cafeteria are convincing holograms that would have fooled anyone. The only real cup in the cafeteria is the one that Coop saw.

GUARDIAN ANGEL*: This case is exactly like FAKE CUPS except that Coop is guarded by a guardian angel, who will ensure that Coop never forms false beliefs. The angel will not intervene with Coop's beliefforming process if he is about to form a true belief, but will stop the belief-forming process if Coop is about to form a false belief. Moreover, the angel has tremendous interest that Coop does not form any false beliefs, and therefore she is guarding Coop in all possible worlds. Since Coop looks at the only real cup in the cafeteria, and forms a true belief as a result, the angel does not interrupt Coop's belief-forming process. ${ }^{6}$

Intuitively, Coop does not know in FAKE CUPS but knows in GUARDIAN ANGEL* that a cup is in front of him. Moreover, the safety condition can be used to explain this difference. After all, Coop's belief is unsafe in FAKE CUPS but safe in GUARDIAN ANGEL*. The question we need to ask is whether Coop's cognitive abilities contribute to the explanation as to why his belief is safe.

\footnotetext{
${ }^{6}$ Luper (2006) has offered a similar thought experiment to demonstrate an altogether different point. Luper argues convincingly that cases similar to the GUARDIAN ANGEL* are genuine cases of knowledge.
} 
I think it is relatively clear that Coop's cognitive abilities do not help to explain the safety of his epistemic standing. After all, GUARDIAN ANGEL* is identical to FAKE CUPS with respect to Coop's cognitive abilities and their operations, but in FAKE CUPS, Coop's belief is unsafe. What explains the safety of Coop's epistemic standing in GUARDIAN ANGEL* has everything to do with the presence of the guardian angel, and nothing with Coop's cognitive abilities or his epistemic performance. ${ }^{7}$ Given that GUARDIAN ANGEL* is a case of knowledge where the subject's cognitive abilities neither enhance nor help to explain the safety of the subject's epistemic state, virtue epistemologists cannot hope to elude the problem that the guardian angel* case poses by reinterpreting the contribution thesis in the suggested way.

Finally, let us look at the ramifications of this result. First of all, it should be evident that the presented counterexample alone does not suffice to show that there is no possible formulation of the virtue-theoretic condition that would not elude the problem posed by the counterexample. The critique that I have offered is targeted only at those virtue epistemological theories of knowledge that are committed to the contribution thesis. It might be thought that this diminishes the impact of the counterexample. However, I have argued that virtue epistemologists who think that a virtue-theoretic condition and a safety condition are necessary for knowledge are committed to the contribution thesis, because they want the virtue-theoretic component of their view to contribute to the safety of the subject's belief. This is true of both modest and robust virtue epistemologists. Notice also that even those virtue epistemologists who reject the safety condition will have a hard time rejecting the contribution thesis. The reason for this is that it is hard to see how one's cognitive abilities could contribute to the correctness of one's belief without thereby contributing to its safety. Moreover, it seems that it is the contribution thesis that allows the virtue epistemologist to deal with some pressing counterexamples, such as cases of testimonial knowledge and cases featuring environmental luck. Furthermore, by accepting the contribution thesis, the robust virtue epistemologist is able to accept the epistemic dependency thesis advocated by Kallestrup and Pritchard. In short, if the contribution thesis were true, virtue epistemologists would be very well off.

Sadly, however, virtue epistemological theories of knowledge that accept the contribution thesis are untenable. There are cases of knowledge where a subject's cognitive abilities do not enhance the subject's

\footnotetext{
${ }^{7}$ Reed $(2009,97)$ has argued that virtue epistemological theories of knowledge do not have the resources to explain the epistemic difference between cases like FAKE CUPS and GUARDIAN ANGEL*.
} 
epistemic position with respect to her inquiry. If we accept the contribution thesis, we should conclude that there are cases of knowledge where the truth of a subject's belief is not attributable to her cognitive agency. The virtue epistemologist is thus not able to accept the contribution thesis, even though she seems committed to it.

\section{Two Ways to Preserve Our Virtue}

What should the virtue epistemologist do? The most straightforward way of dealing with the problem would be to reject the contribution thesis. The problem with this response is that robust virtue epistemologists would have a difficult time maintaining the entailment thesis. If the subject's cognitive abilities do not have to contribute at all to the safety of the subject's belief when the truth of that belief is properly attributable to the subject's cognitive abilities, then it is hard to see what would ensure that the subject's belief is safe. Any robust virtue epistemologist who endorses the entailment thesis while rejecting the contribution thesis would owe us an explanation as to why the entailment thesis is true. If the robust virtue epistemologist is not able to provide such an explanation, then keeping the entailment thesis while rejecting the contribution thesis would be an ad hoc move.

But rejecting the entailment thesis would leave modest virtue epistemology intact. Perhaps we should opt for modest virtue epistemology instead? Alas, even modest virtue epistemology would suffer from rejecting the contribution thesis, since modest virtue epistemologists maintain that the virtue-theoretic condition and the safety condition are tied together in a dynamic way. Therefore, virtue epistemologists should abandon the idea that in all cases of knowledge the cognitive success that the subject attains is attributable to her cognitive abilities.

Strangely enough, this need not mean the end of virtue epistemology. Epistemic virtues might still have a central place in the analysis of knowledge. Nothing has been said to undermine the claim that only virtuously formed beliefs are in the market of knowledge. But surely a true belief that is virtuously formed does not necessarily amount to knowledge. In Gettier cases, the subjects gain true beliefs through virtue but nevertheless lack knowledge. I will briefly offer two possible ways in which we could continue to do virtue 
epistemology while abandoning the idea that in cases of knowledge the cognitive success that the subject attains has to be attributable to the subject's cognitive abilities.

The first option is to go 'knowledge-first'. The direct virtue epistemology, developed by Miracchi (2015), seems to be able to deal with the guardian angel case. ${ }^{8}$ Direct virtue epistemology differs from the traditional 'indirect' virtue epistemology in that it conceives the cognitive abilities that are relevant for knowledge possession as abilities to know, rather than as abilities to gain true beliefs. The question whether direct virtue epistemology is able to deal with the guardian angel case hinges on how we understand the following passage:

The manifestation conditions of [competences to know] are whatever operations of subpersonal cognitive mechanisms and external conditions together (against a background of possession of [competences to know]) constitute a particular case of knowing that $p$ in the way characteristic of the competence $[\ldots]$.

A competence to know is manifested just in case its manifestation conditions obtain. (Miracchi 2015, 45-46)

Clearly, in the guardian angel case, there is a set of cognitive operations and external conditions that together constitute Agnes's knowledge. This applies to all cases of knowledge. The question is whether the cognitive operations and external conditions that constitute Agnes's knowledge constitute it in the way characteristic of the relevant competence. This is a difficult question, since Agnes's circumstances are so peculiar. However, I think that there is no obvious reason to deny that Agnes gains knowledge in GUARDIAN ANGEL in pretty much the same way that she gains it in ORDINARY PERCEPTION, and hence her cognitive operations and the external conditions seem to constitute her knowledge in a way characteristic of the relevant competence. Therefore, direct virtue epistemology can accommodate the guardian angel case.

Of course going 'knowledge-first' has its costs. Most importantly for our purposes, by moving to the knowledge-first camp, one must leave behind the, perhaps hopeless but nevertheless extremely addictive,

\footnotetext{
${ }^{8}$ In addition to Miracchi, knowledge first virtue epistemological accounts have been developed by Millar (2010), Kelp (2016b, 2017, forthcoming), and Silva (forthcoming).
} 
project of trying to offer a non-circular analysis of knowledge. Perhaps we should do this, but there is yet another way available for the virtue epistemologist.

If we abandon the idea that in cases of knowledge the cognitive success that the subject attains is attributable to one's cognitive abilities, we can still hold onto the intuitive idea that knowledge is always gained through virtue. We noted above that this minimal virtue-theoretic condition is not able to deal with Gettier cases on its own. We need to combine this minimal virtue-theoretic component with a condition that is not satisfied in Gettier cases.

A natural candidate for such a condition is SAFETY. After all, the virtue epistemologists we have been discussing are already committed to a properly formulated safety condition, and SAFETY seems to be just such a condition. Recall that SAFETY is relativized to the method of belief-formation that the subject uses in the actual world. The most straightforward way to combine the minimal virtue-theoretic condition with SAFETY would be to relativize SAFETY in terms of virtuous epistemic methods that the subject uses in the actual world. This move would ensure that all safe beliefs would be virtuously formed. Here is the virtuetheoretic version of the safety condition:

VIRTUOUS SAFETY: S knows that $p$ only if

(i) in nearly all nearby possible worlds, and in all of the very closest possible worlds, where S believes that $p$ (via the same virtuous method $\mathrm{V}$ that she uses in the actual world), her belief will continue to be true.

VIRTUOUS SAFETY combines the minimal virtue-theoretic condition and the safety condition in an elegant way. ${ }^{910}$ Retreating to VIRTUOUS SAFETY would not mean the end of the virtue-theoretic program, since there would still be a lot of virtue epistemology to do. Casting light on the nature and metaphysics of

\footnotetext{
${ }^{9}$ I have argued elsewhere (2017b) that by relativizing the safety condition to virtuous methods of belief formation, the safety theorist is able to solve the generality problem that plagues reliabilism.

${ }^{10}$ By endorsing VIRTUOUS SAFETY, we reject the idea that the virtue-theoretic condition should be connected to the safety condition in a dynamic way. We have no reason to tie the virtue-theoretic condition and the safety condition together in a dynamic way, because we have rejected the idea that in all cases of knowledge, the cognitive success that the subject attains is attributable to the subject's cognitive abilities. This does not, however, mean that there is no connection between one's epistemic virtues and the safety of one's beliefs in cases of knowledge. On the contrary, by relativizing the safety condition to virtuous methods of belief formation, we ensure that in all cases of knowledge the subject must arrive at a true belief by exercising her cognitive abilities. What we do not require is that the fact that the subject arrived at a true belief would have to be creditable to the subject's cognitive abilities.
} 
epistemic virtues would be an important part of the project of anyone who advocated VIRTUOUS SAFETY. Moreover, the virtue epistemologist would still be in the running to offer a reductive analysis of knowledge, since unlike the direct virtue epistemology advocated by Miracchi, an analysis of knowledge in terms of VIRTUOUS SAFETY is not obviously circular. That does not mean that a theory of knowledge that advanced VIRTUOUS SAFETY would be preferable to direct virtue epistemology. It is simply another way to continue the virtue-theoretic research program.

\section{Concluding Remarks}

Let me briefly summarize what I have argued. Robust virtue epistemologists have had a hard time dealing with cases of environmental luck and with cases of testimonial knowledge. By advancing the entailment thesis, robust virtue epistemologists are able to deal with cases of environmental luck. Modest virtue epistemologists do not accept the entailment thesis, but instead claim that we should add a safety condition to the virtue-theoretic condition in order to be able to deal with such cases. Interestingly, both modest and robust virtue epistemologists think that the virtue-theoretic condition and the safety condition need to be tied together in a dynamic way, and hence accept the contribution thesis. Crucially, by advancing the contribution thesis, the virtue epistemologist is able to deal with cases of environmental luck and with cases of testimonial knowledge. Moreover, by accepting the contribution thesis, the virtue epistemologist is able to accept the epistemic dependency thesis.

Alas, the contribution thesis, together with the virtue-theoretic condition, has a clear-cut counterexample. In the guardian angel case, Agnes gains knowledge even though the truth of her belief is not attributable to her cognitive agency according to the contribution thesis. Therefore, either the contribution thesis or the virtuetheoretic condition is false, or both are false. Given that it is the contribution thesis that allows the virtue epistemologist to deal with most of the troublesome objections, abandoning it does not seem to be an option. Therefore, it seems that we ought to abandon the idea that in all cases of knowledge the truth of one's belief is attributable to one's cognitive abilities.

I presented two possible ways how we might continue to practice virtue epistemology while rejecting this claim. The first option is to go knowledge-first. The second option is to marry a minimal virtue-theoretic 
condition, which states that in cases of knowledge the subject's true belief has to be formed through cognitive virtue, with an anti-luck condition that is able to deal with Gettier cases. This led us to VIRTUOUS SAFETY. A theory of knowledge that accepted VIRTUOUS SAFETY would be a modest virtue epistemological theory, but given that it is not committed to the idea that in cases of knowledge one's cognitive success is attributable to one's cognitive abilities, it would have much weaker commitments than its predecessors, and therefore it might be preferable to them.

\section{Acknowledgements}

I would like to thank audiences at Edinburgh, Notre Dame, Leuven, and Helsinki, where earlier versions of this paper were presented. Special thanks to Robert Audi, Benoit Gaultier, John Greco, Markus

Lammenranta, Maria Lasonen-Aarnio, Ram Neta, Duncan Pritchard, Declan Smithies, and an anonymous referee of Grazer Philosophische Studien for comments that helped to improve the paper.

\section{References}

Bogardus, Tomas 2014. "Knowledge Under Threat." Philosophy and Phenomenological Research 88, 289 313.

Carter, Adam 2016. "Robust Virtue Epistemology as Anti-luck Epistemology: A New Solution." Pacific Philosophical Quarterly 97, 140-155.

Gaultier, Benoit 2014. "Achievements, Safety and Environmental Epistemic Luck." Dialectica 68, 477-497.

Goldman, Alvin 1976. "Discrimination and Perceptual Knowledge." Journal of Philosophy 73, 771-791.

Greco, John 2007. "Worries about Pritchard's Safety." Synthese 158, 299-302.

Greco, John 2010. Achieving Knowledge: A Virtue Theoretic Account of Epistemic Normativity. Cambridge: Cambridge University Press.

Greco, John 2012. "Better Safe than Sensitive." In: The Sensitivity Principle in Epistemology. Edited by Kelly Becker and Tim Black, Cambridge: Cambridge University Press, 193-206.

Greco, John 2016. "Knowledge, Virtue, and Safety." In: Performance Epistemology - Foundations and Applications. Edited by Miguel Angel Fernández Vargas, Oxford: Oxford University Press, 51-61.

Hawthorne, John, and Lasonen-Aarnio, Maria 2009. "Knowledge and Objective Chance." In: Williamson on Knowledge. Edited by Patrick Greenough and Duncan Pritchard, Oxford: Oxford University Press, 92-108.

Hirvelä, Jaakko 2017a. "Is it Safe to Disagree?" Ratio 30, 305-321.

Hirvelä, Jaakko 2017b. "Global Safety: How to Deal with Necessary Truths." Synthese (online first) https://doi.org/10.1007/s11229-017-1511-z

Kallestrup, Jesper, and Pritchard, Duncan 2013. "Robust Virtue Epistemology and Epistemic Dependence." In: Knowledge, Virtue and Action: Putting Epistemic Virtues to Work. Edited by Tim Henning and David Schweikard, New York: Routledge, 209-227.

Kelp, Christoph 2016a. "Epistemic Frankfurt Cases Revisited." American Philosophical Quarterly 53, 2737.

Kelp, Christoph 2016b. "Justified Belief: Knowledge First-Style." Philosophy and Phenomenological Research 93, 79-100. 
Kelp, Christoph 2017. "Lotteries and Justification." Synthese 194, 1233-1244.

Kelp, Christoph forthcoming. "Knowledge First Virtue Epistemology." In: Knowledge First: Approaches in Epistemology and Mind. Edited by Adam Carter, Emma Gordon and Benjamin Jarvis. Oxford: Oxford University Press.

Lackey, Jennifer 2007. "Why We Don't Deserve Credit for Everything We Know." Synthese 158, 345-361.

Lackey, Jennifer 2009. "Knowledge and Credit." Philosophical Studies 142, 27-42.

Littlejohn, Clayton 2014. "Fake Barns and False Dilemmas." Episteme 11, 369-389.

Luper, Steven 2003. "Indiscernability Skepiticism." In: The Skeptics: Contemporary Essays. Edited by Steven Luper, Aldershot: Ashgate, 183-202.

Luper, Steven 2006. "Restorative Rigging and the Safe Indication Account." Synthese 153, 161-170.

Millar, Allan 2010. "Knowledge and Recognition." In: The Nature and Value of Knowledge. Edited by Duncan Pritchard, Allan Millar and Adrian Haddock. Oxford: Oxford University Press, 89-188.

Miracchi, Lisa 2015. "Competence to Know." Philosophical Studies 172, 29-56.

Neta, Ram, and Rohrbaugh, Guy 2004. "Luminosity and the Safety of Knowledge." Pacific Philosophical Quarterly 85, 396-406.

Pritchard, Duncan 2005. Epistemic Luck. Oxford: Oxford University Press.

Pritchard, Duncan 2007. "Anti-luck Epistemology." Synthese 158, 277-297.

Pritchard, Duncan 2010. "Knowledge and Understanding." In: The Nature and Value of Knowledge. Edited by Duncan Pritchard, Allan Millar and Adrian Haddock, Oxford: Oxford University Press, 5-88.

Pritchard, Duncan 2012. "Anti-luck Virtue Epistemology." Journal of Philosophy 109, 247-279.

Pritchard, Duncan 2015. "Anti-luck Epistemology and the Gettier Problem." Philosophical Studies 172, 93 111.

Reed, Baron 2009. "A New Argument for Skepticism." Philosophical Studies 142, 91-104.

Sainsbury, Richard 1997. "Easy Possibilities." Philosophy and Phenomenological Research 57, 907-919.

Silva, Paul forthcoming. "Knowing How to Put Knowledge First in the Theory of Justification." Episteme.

Sosa, Ernest 1999. "How to Defeat Opposition to Moore." Philosophical Perspectives 13, 141-154.

Sosa, Ernest 2007. A Virtue Epistemology: Apt Belief and Reflective Knowledge: Volume I. Oxford: Oxford University Press.

Sosa, Ernest 2009. Reflective Knowledge: Apt Belief and Reflective Knowledge, Volume II. Oxford: Oxford University Press.

Sosa, Ernest 2011. Knowing Full Well. Princeton: Princeton University Press.

Sosa, Ernest 2015. Judgment and Agency. Oxford: Oxford University Press.

Turri, John. 2016 "Knowledge as Achievement, More or Less." In: Performance Epistemology - Foundations and Applications. Edited by Miguel Angel Fernández Vargas, Oxford: Oxford University Press, 124-134.

Williamson, Timothy 2000. Knowledge and Its Limits. Oxford: Oxford University Press. 